\title{
EL SUEÑO DEL CELTA O ELARTE DE LA DENUNCIA
}

\author{
Eloy Urroz
}

\begin{abstract}
Este ensayo se enfoca en dos cuestiones esenciales de El sueno del celta. En primer lugar, en la posición política y ética de Vargas Llosa frente al genocidio del Congo y el Putumayo a principios del siglo XX debido a las repetidas invasiones extranjeras y nacionales codiciosas del caucho o látex negro. En este sentido — se señala - la posición vargasllosiana estará decididamente influida por el pensamiento del filósofo austríaco Karl Popper y la lectura de su obra cimera, $L a$ sociedad abierta y sus enemigos. En segundo lugar, este tra-
\end{abstract}

Eloy Urroz (Nueva York, 1967) es autor de las novelas Las leyes que el amor elige (1993), Las Rémoras (1996), Las almas abatidas (2000), Un siglo tras de mi (2004), Fricción (2008) y La familia interrumpida (2011). Junto con Jorge Volpi e Ignacio Padilla publicó Tres bosquejos del mal (1994), coeditó con Volpi Dos novelitas poco edificantes (2003) y más tarde Crack: Instrucciones de uso (2004). Ha escrito los ensayos: Las formas de la inteligencia amorosa: D. H. Lawrence y James Joyce (1999), La silenciosa herejía: Forma y contrautopía en las novelas de Jorge Volpi (2000), Siete ensayos capitales (2004) y Êthos, forma, deseo entre España y México (2007). Asimismo ha publicado los libros de poesía: Ver de viento (1988), Sobre cómo apresar la vida de las estrellas (1989), Yo soy ella (1998), Poemas en exhibición (2003) y Yer blues (2011), así como la crónica política El águila, la serpiente y el tucán (2000). Varias de sus novelas han sido traducidas al inglés, francés, italiano, alemán y portugués. Actualmente es profesor de literatura latinoamericana en The Citadel College, en Charleston, South Carolina. Eloyurroz@hotmail.com.

Estudios Públicos, 122 (otoño 2011) 
bajo se da a la tarea de desentrañar la forma helicoidal en que Vargas Llosa ha estructurado la historia de su protagonista, Roger Casement. Al lado del análisis formal, se explican las posibles razones por las cuales la tercera parte de El sueño del celta, "Irlanda", tiende a ralentizarse. Entre ellas Urroz destaca un cierto abuso de la historia recabada en detrimento de la imaginación creadora en el cuerpo de la narración.

\section{1}

$\mathrm{H}$ a sido un ejercicio interesante releer La ciudad y los perros inmediatamente después de concluir El sueño del celta. En esta ocasión, releí la primera novela de Vargas Llosa por razones académicas (se trataba de un curso dedicado enteramente al novelista peruano entre estudiantes norteamericanos subgraduados). En cambio, su última novela la he leído por solaz, por adicción vargasllosiana. A pesar de ello, algo curioso aconteció y paso a referirlo escuetamente: conforme avanzaba en mi lectura de El sueño del celta, mi interés o fruición desvanecía, mi lectura de placer se volvía, a intervalos, farragosa, especialmente en la última de sus tres grandes partes titulada "Irlanda". Algo similar les había acontecido a dos excelentes lectores que conozco. Cuando éstos arribaron a la tercera sección del libro, "Irlanda", es decir, 350 páginas luego de comenzada la lectura, ésta de pronto se ralentizó, se hizo espasmódica, algo más o menos semejante a lo ocurrido a otros lectores avezados con El Paraíso en la otra esquina, especialmente en los capítulos dedicados a la sindicalista Flora Tristán y sus largas y monótonas luchas obreras en París. Al tratar de ahondar en las posibles razones por las que ocurre lo anterior se aboca este trabajo. Insisto: he leído la última novela del escritor peruano como la mayoría, por placer, por adicción y ansioso por repetir (vivir) el mecanismo de artificio al que Vargas Llosa nos tiene acostumbrados desde hace medio siglo. En cambio, he releído por tercera ocasión La ciudad y los perros por otros motivos (motivos pedagógicos) y para estar a la par que mis estudiantes. Una lectura futura de El sueño del celta tal vez me permita hallar claves fundamentales en la obra y unirla al grupo de sus mejores cuatro o cinco 
producidas hasta el día de hoy ${ }^{1}$, pues lo cierto es que El sueño del celta conjuga (tanto como La guerra del fin del mundo, La fiesta del Chivo, La casa verde y Conversación en La Catedral) voluntad totalizadora con voluntad formal, una clara concepción artística jamás supeditada a una visión política o ideológica y, sobre todo, un impresionante despliegue histórico y social aunado a una aguda interpretación biográfica del protagonista. A pesar de estos atributos, habría que mencionar una cuestión que El sueño del celta no tiene y La ciudad y los perros conserva a cincuenta años de haber sido publicada. Se trata de una cualidad que ninguna otra novela de Vargas Llosa muestra con tanta nitidez: su estilo. La ciudad y los perros es, sobre todo, una obra de estilo, y si toda novela es, finalmente, lenguaje y sintaxis, como apunta Vargas Llosa, $L a$ ciudad y los perros lo es probablemente menos que ninguna: destruye ese orden y hace añicos el lenguaje y la sintaxis con claro conocimiento de causa. Nada de lo anterior vuelve a suceder (o al menos no de tal manera y en tal grado) en las novelas posteriores, mucho menos en sus últimas tres grandes obras donde lo anterior brilla por su ausencia: $L a$ fiesta del Chivo, El Paraíso en la otra esquina y El sueño del celta ${ }^{2}$.

Pero ¿por qué disminuye esta especie de riesgo estilístico?, ¿se desvanece de modo gradual, en cada novela, o bien, retorna por épocas? Vargas Llosa, lo sabemos, es un autor metódico, claro, obsesivo de la verdad aunque comprenda, como Popper, su maestro ${ }^{3}$, que a ella nunca se llega. Él mismo se ha jactado de ser un escritor de oficio en el mejor sentido de la palabra, un autor flaubertiano con todo lo que esto implica. Por ello, décadas y lustros de oficio escritural (oficio estrictamente novelístico) han afilado y decantado su estilo hasta límites insospechados. No sólo la sintaxis y la gramática es (debe ser) impecable; se trata de la claridad de esa gramática, de su orden interno, de la confianza que Var-

${ }^{1}$ En la presentación del libro en la FIL (Feria Internacional del Libro, en Guadalajara) el pasado mes de noviembre, José Miguel Oviedo hizo esta confesión pública.

${ }^{2}$ Travesuras de la niña mala representa, sin embargo, un caso aparte en esta serie de novelas publicadas en la última década. No sólo es su mejor novela de amor (acaso su única novela de amor), sino también una de sus cuatro o cinco mejores novelas publicadas a la fecha. No obstante, éste no es el mejor sitio para comentarla.

${ }^{3}$ Recomiendo ver mi ensayo "Karl Popper y Mario Vargas Llosa: ¿Libertad o igualdad?", 2011, para la relación del escritor peruano con el filósofo austríaco. 
gas Llosa le atribuye y deposita (después de años de experiencia y lucha con la palabra) al signo lingüístico que va a expresar un significado específico. Esta hiperconciencia lo hace incluso (en estos últimos años) más racional que nunca, más claro y metódico de lo que, de hecho, siempre ha sido. Vargas Llosa está convencido de que su labor (su oficio de escritor) es, ante todo, el de un artista que transmite (y representa) un mensaje con apabullante claridad, meticulosidad, sin devaneo y sin ambigüedades. La comunicación lo es todo. Popper y su crítica despiadada al oscuro discurso hegeliano pueden estar detrás de ello; incluso más que el propio Flaubert y su pasión por le mot just. Y ése es, paradójicamente, el posible origen del problema que acarrean algunos pasajes de El sueño del celta como tendré ocasión de analizar. Sin embargo, tal vez no se trate de un problema; quizás estemos presenciando un cambio en el estilo, una evolución más o menos gradual hacia la certidumbre del signo, hacia la claridad del mensaje y la fiabilidad (a ultranza) de la comunicación. No deja de resultar curioso, sin embargo, que justo acontezca esta suerte de evolución estilística cuando más admiración profesa Vargas Llosa a un autor que hizo de lo contrario un arte narrativo: Juan Carlos Onetti. Nada más diametralmente opuesto a Cuando ya no importe, Dejemos hablar al viento o El astillero que una novela tan bien trabada, tan claramente estructurada y transmitida, tan fiablemente armada y documentada, como El sueño del celta. En esta última no encontraremos asomo de ambivalencia, incertidumbre, devaneo o duda. El lenguaje transmite fielmente el arte del autor, y el arte del autor es, aunque no lo pretenda, su estilo. Éste ha sido conscientemente sacrificado, crucificado, en aras de la fiabilidad y la transparencia narrativas (Camus y Hemingway son asimismo sus maestros). Vargas Llosa ha evolucionado entonces hacia un arte de la razón y la claridad. No está mal, insisto. Sencillamente es un arte distinto. El precio, si lo hubiera, es que el lenguaje ya no será el principal motor o personaje de la historia, el estilo no será la anécdota ni el vehículo de la narración y viceversa; en resumen: el estilo ya no es preponderantemente la forma. Cuanto más, éste sirve otro propósito: comunicar fielmente, transmitir el mensaje y expresar ese mensaje sintácticamente (ordenadamente) y del modo más próximo al pensamiento racional, al pensamiento analítico y deductivo de un autor en la cima de la claridad mental. Vargas Llosa es, en su madurez, un novelista capaz de desdoblarse y ver, desde fuera, los propios vicios o virtudes de su prosa; un autor capaz de organizar y concatenar 
sus materiales novelísticos (toda la información recabada) con un único y solo empeño: que el estilo pretenda no estar, no existir, que el estilo resulte directo, llano y consiga representar, lo más acuciosamente posible, el material que se pretende contar. Esa selva, caos o enjambre que el lector percibió en La ciudad y los perros, no lo encuentra cincuenta años más tarde en El sueño del celta.

\section{2}

Aunque no autobiográfica, El sueño del celta proyecta varios rasgos biográficos del propio novelista en el personaje de Roger Casement. Ya desde las primeras páginas nos encontramos con la descripción de algunas características psicológicas del niño irlandés, las cuales, todas las distancias salvadas, parecieran extraídas de El pez en el agua, las memorias de Mario Vargas Llosa. Veamos.

En el capítulo II, leemos, por ejemplo, que:

Pero no eran los hechos de armas lo que más encandilaba la imaginación del pequeño Roger, sino los viajes, abrir caminos por paisajes nunca hollados por el hombre blanco, las proezas físicas de resistencia, vencer los obstáculos de la naturaleza. $\mathrm{Su}$ padre era entretenido pero severísimo y no vacilaba en azotar a sus hijos cuando se portaban mal, incluso a Nina, la mujercita, pues así se castigaban las faltas en el Ejército y él había comprobado que sólo esa forma de castigo era eficaz. Aunque admiraba a su padre, a quien Roger quería de verdad era a su madre [...] Una de las primeras cosas que aprendería fue — ¿tenía cinco, seis años? - que sólo podía correr a echarse en brazos de su madre cuando el capitán no estaba cerca (p. 20).

A diferencia de Jorge Luis Borges, quien quedaba encandilado de niño por los hechos y proezas de armas y héroes militares, esta vez serán las aventuras y hazañas las que enajenen la imaginación del adolescente Vargas Llosa y del niño irlandés de El sueño del celta. Lo mismo que el padre de Alberto, el Poeta, o el padre de Ricardo Arana, el Esclavo — ambos personajes de La ciudad y los perros, ambos tomados del recuerdo fresco del joven Vargas Llosa a fines de los cincuenta cuando redactaba su primera novela-, el padre de Roger Casement es "severísimo", de una severidad que no lo hace dudar al momento de azotar 
a sus hijos y a su hija Nina cuando es necesario hacerlo. Para colmo, esa misma disciplina militarizada que Vargas Llosa tanto ha abominado y denunciado en ¿Quién mató a Palomino Molero?, Pantaleón y las visitadoras, Historia de Mayta o La ciudad y los perros, reaparece en la crítica que Casement indirectamente hace a la férrea disciplina de su padre, a quien, de paso, sólo admira, pero no quiere. A quien Roger Casement verdaderamente ama es, lo mismo que Vargas Llosa, a su madre. Y de la misma manera que el novelista peruano confesaba en sus memorias la súbita distancia que se apoderó entre su madre y él a raíz de la llegada del desaparecido padre, Roger Casement sabe desde muy pequeño que no debe correr a echarse en brazos de su madre cuando su padre, el capitán, se encuentre cerca de ellos. Son estos duros aprendizajes los que marcarán la niñez de ambos individuos de manera indeleble $\mathrm{y}$, por lo mismo, serán éstos también sus fieles "demonios personales".

Sin embargo, las similitudes no paran aquí. Veamos.

Lo mismo que Alberto y Vargas Llosa cuando era niño, Roger Casement escribía poesía y devoraba libros desde muy temprana edad. Lo mismo que el héroe irlandés, Vargas Llosa leía aquellos folletos que describían las proezas y hazañas de los héroes de sus novelas favoritas: Los miserables y El conde de Montecristo. En el caso de Casement, leemos que "el niño vivió la novelesca historia del doctor David Livingstone con asombro y envidia" (p. 24). Ambos, Vargas Llosa y Casement, quisieron, asimismo, desde niños, vivir "vidas tan extraordinarias" (p. 25) como la de los héroes que describían los libros y folletos que devoraban. Lo mismo que Casement en su edad adulta, Vargas Llosa jamás fue amigo de fiestas, bares y prostíbulos ${ }^{4}$. En El sueño del celta, leemos, por ejemplo, que Casement era "enemigo de francachelas, casi no bebía y jamás se le vio frecuentar los bares y lupanares del puerto" (p. 25) y, al igual que Vargas Llosa: "Desde entonces fue un fumador empedernido" (p. 26). Por último, y para cerrar este cúmulo de analogías, intuimos la clase de personaje que Casement ha sido cuando nos enteramos que "su pasión por África y su empeño en hacer méritos en la compañía lo llevaban a leerse con cuidado, llenándolos de anotaciones, los folletos y las publicaciones que circulaban por las oficinas relacionadas con el comercio marítimo entre el Imperio británico y el África Occidental” (p. 26). ¿No podríamos imaginar (visualizar) al mismo Mario Vargas Llosa en aquella

${ }^{4}$ El pasaje ¿biográfico? de La casa verde e Historia secreta de una novela es una excepción a la regla y acaece durante su adolescencia. 
vieja buhardilla parisina hacia 1964 escribiendo La casa verde en circunstancias bastante similares, es decir, leyendo con cuidado y llenando de anotaciones los folletos, mapas y publicaciones relacionados con la Amazonía peruana y la miserable situación de los aborígenes explotados por culpa de la codicia que despertó el caucho (látex negro) en Occidente a principio del siglo XX? Ambos métodos de trabajo, ambos empeños, ambos caracteres disciplinados y tenaces, dejan pocas dudas del porqué Vargas Llosa se sintió imantado hacia la figura del famoso héroe irlandés (sus "demonios" eran casi idénticos a los "demonios" de Casement). Si a todo lo anterior sumáramos la casualidad (o fortuna) que implicó el que el explorador irlandés hubiese estado justamente en la Amazonía peruana y en los mismos recónditos parajes que Vargas Llosa visitó en 1958 - y el hecho contiguo de que esta visita informara su segunda novela-, entonces no podemos sino concluir que El sueño del celta estaba llamada a ser escrita tarde o temprano por el gran novelista peruano.

¿Hasta dónde debemos legitimar la transgresión, el atropello o invasión a los derechos inalienables del otro? O, bien, tal y como le dice el famoso explorador Henry Morton Stanley a Roger Casement hacia 1884 durante su primera expedición en el África: "Poco a poco reemplazarán sus costumbres bárbaras por las de seres modernos e instruidos. Si supieran lo que hacemos por ellos, nos besarían los pies. Pero su estado mental está más cerca del cocodrilo y el hipopótamo que de usted y de mí. Por eso, nosotros decidimos por ellos los que les conviene y les hacemos firmar esos contratos" (p. 43).

Independientemente de que sea o no cierta la categorización del famoso explorador enviado por el rey belga Leopoldo II a abrir la ruta comercial en el Congo, de quien presumiblemente Conrad tomó rasgos para la creación del personaje de Kurtz en Heart of Darkness, la pregunta popperiana que incide una y otra vez oblicuamente a lo largo de El sueño del celta es la siguiente: ¿tenemos el derecho o la obligación moral de "reemplazar" unas costumbres por otras (fueran éstas "modernas" o no, "instruidas" o no)?, ¿debemos civilizar a los otros?, ¿es acaso nuestra razón de ser en la Tierra, nuestra obligación ética o religiosa, ayudar y enderezar a los demás, a esos que no son como nosotros?, ¿es 
acaso nuestro deber "decidir" por los oprimidos y hacer por ellos lo que les "conviene", según nuestro punto de vista, nuestra razón o nuestra ética particular? La pregunta (o preguntas) son arduas, más complicadas de lo que, en apariencia, podrían ser (y aquí veremos por qué).

Para empezar, podríamos traer a colación la situación que ejemplifica la novela con otra semejante si, por ejemplo, nos hiciéramos la siguiente pregunta: ¿debemos intervenir en Libia o en Ruanda y la antigua Yugoslavia, o bien debemos dejar que se autodeterminen los pueblos a través de la lucha interna y fratricida, y que, bueno, simplemente gane el más fuerte? ¿Debemos dejar que sobrevivan los fuertes y perezcan los débiles de Bosnia, Libia, Ruanda, Guatemala y Afganistán? Otra vez Henry Morton Stanley responde darwinianamente: "El África no se ha hecho para los débiles. Las cosas que le preocupan son un signo de debilidad [...] En el África los débiles no duran” (p. 42). ¿Debemos pues intervenir o dejar que los débiles perezcan a manos de los fuertes... llámense poderosas tribus vecinas africanas, mercaderes de esclavos de Zanzíbar, facciones enemigas, razas pretendidamente superiores o civilizaciones poderosas como la belga? Y si debemos intervenir, ¿cómo hacerlo, hasta dónde es legítimo hacerlo? Evidentemente, la novela de Vargas Llosa apunta hacia dos tipos de intervención o legitimación: la de aquellos que intervienen con fines de lucro, explotación y codicia sin reparar en el daño o crueldad producida, y la de aquellos que intervienen con fines altruistas, filantrópicos, llámense misiones cristianas, modernizadoras o llámese Roger Casement y su largo historial de denuncias (contra Leopoldo II, contra la Peruvian Amazon Company de Julio C. Arana, contra el gobierno colonizador inglés, contra la hipocresía y las falsas buenas costumbres de su época, contra la codicia, la crueldad y la maldad humanas). Desde un inicio oímos en tercera persona indirecta libre el pensamiento de Casement cuando leemos: “...suponía que había un precio que pagar. Era inevitable que se cometieran abusos. Entre los colonizadores no sólo vendría gente altruista como el Doctor Livingstone, sino pillos abusivos, pero hechas las sumas y las restas, los beneficios superarían largamente a los prejuicios. La vida africana le fue mostrando que las cosas no eran tan claras" (p. 44). Este cambio gradual de perspectiva en Casement, bien visto, tiene grandes parangones con el cambio que el mismo Vargas Llosa fue sufriendo a partir de su lectura de Karl Popper y su distanciamiento del comunismo. En el juego de las sumas y las restas, no debemos jamás justificar las restas, 
menos aducir que hay indefectiblemente "un precio que pagar". Ésa es la enseñanza popperiana pues de ahí al totalitarismo hay un solo y pequeño paso. Por lo mismo, tal y como leemos al final del párrafo citado, "las cosas no eran tan claras". Igualmente, las cosas no fueron ni han sido tan claras para muchos de sus detractores. Ya desde 1990, el escritor peruano reconocía que "las sociedades totalitarias modernas han dado un impulso grande a la educación, la salud, el deporte, el trabajo, poniéndolos al alcance de las mayorías [...] Pero cuando un Estado, en su afán de controlarlo y decidirlo todo arrebata a los seres humanos el derecho de inventar y de creer las mentiras que a ellos les plazcan [se refiere a la libertad de escribir y leer ficciones], un gran centro neurálgico de la vida social queda abolido. Y hombres y mujeres padecen una mutilación que empobrece su existencia aun cuando sus necesidades básicas se hallen satisfechas"5.

Pero volviendo al asunto que nos atañe, ambas facciones "colonizadoras" no dejan de ser, a pesar de ellas mismas, una suerte de hermanas gemelas pues las dos se sienten impelidas, a su muy particular manera, a intervenir, a actuar y a meterse en lo que no es de su incumbencia. Han hecho del problema del otro un serio problema individual, moral y, en algunos casos, hasta un problema patriótico; ambos grupos se sienten legitimados a cambiar las cosas aunque sus fines sean diametralmente opuestos. Por lo mismo, la pregunta inicial sigue sin responderse todavía: ¿tenemos o no el derecho a intervenir, a imponer o transgredir la libertad y las costumbres del otro cuando se trata de su propia "conveniencia", cuando sabemos o creemos que es "bueno" hacerlo? O tal y como se pregunta Casement: “¿Qué otra manera había de hacerlo? ¿Cómo dar legitimidad a la futura colonización con gente que no podía entender una palabra de esos 'tratados' en los que quedaba comprometido su futuro y el de sus descendientes?" (p. 40). Las respuestas son, como las preguntas, complejas, y encierran a su vez otras (inevitables, difíciles) preguntas, por ejemplo: ¿de qué futuro "comprometido" estamos hablando?, ¿qué significa "conveniencia"?, ¿cuál es el rasero a partir del cual medimos lo "conveniente" o "inconveniente" de un hecho o de una acción en aras de un incierto futuro "comprometido"?, ¿quién puede probar o refutar (y bajo qué punto de vista) una vía o camino a seguir?, ¿cuál es la mejor vía a final de cuentas?, ¿cuál es la

\footnotetext{
${ }^{5}$ La verdad de las mentiras, p. 19.
} 
más óptima o positiva y desde qué ángulo?, ¿quién legitima lo anterior? Y yendo más allá en nuestra pesquisa: ¿acaso lo óptimo o lo positivo, lo que llamamos "lo mejor" o "conveniente", es lo que los demás siempre desean?, y ¿cómo podemos estar seguros de ello si esos otros no hablan nuestra lengua, no tienen nuestro código moral ni nuestras leyes ni costumbres y, sobre todo, si no conocen las consecuencias? Aristotélicamente sabemos que lo bueno es lo mejor y "lo mejor", según el estagirita, se llama eudemia. Nietzscheanamente, sin embargo, no podemos estar ya tan seguros. Los valores se subvierten, transmutan, en cada caso y con el paso del tiempo. No son estáticos y ellos dependen del punto de vista del observador, del valorador (o genealogista) de valores. En este caso, dependen de aquel que tiene el poder, del vencedor y no del vencido, del opresor y no del oprimido. Un caso limítrofe de lo que aduzco es el del memorable personaje de Leaving Las Vegas. Sabemos que este hombre encarnado en Nicolas Cage quiere morir, añora la muerte, y sólo la desea por llevar a cabo su pura y soberana voluntad. ¿Habría que detenerlo? Esta salida (el suicidio gratuito) es para todos los demás habitantes del mundo la peor salida, pero no lo es para el personaje de Cage, lo mismo que no lo es para Kirilov, el famoso suicida de Los demonios, de Dostoyevski. Leamos, por ejemplo, el pasaje en que el ruin Piotr Stepanovich lo visita hacia el final de la novela. Allí Kirilov le dice a rajatabla:

-Yo quiero poner de manifiesto mi voluntad. Quizá sea el único que lo haga, pero lo haré.

—Pues hágalo.

-Estoy obligado a pegarme un tiro porque el nivel más alto de mi voluntad es matarme.

-Pero usted no es el único que se mata; hay muchos suicidas.

-Ésos tienen un motivo. Yo soy el único que lo hace sin motivo alguno, por pura voluntad (p. 760).

Claro: los ejemplos citados son, insisto, el límite de la libertad, y en ambos casos se trata de una libertad empleada (conscientemente) para atentar contra uno mismo, no contra el otro y mucho menos contra un pueblo en franca desventaja. De uno u otro modo, la novela de Vargas Llosa no hace en el fondo sino cuestionar una y otra vez esos sólidos (o no tan sólidos) presupuestos morales, al menos aquellos re- 
lacionados con los límites de nuestra libertad y responsabilidad hacia el otro, el oprimido, el desaventajado, el martirizado. ¿Es más legítima la intervención de Roger Casement que la del explorador Henry Morton Stanley? La respuesta, en un primer estadio, es muy sencilla. Uno denuncia, él otro explota. Uno desea ayudar, el otro invade para ayudar. Uno salva, el otro engaña para salvar. No obstante, al final, ambos creen firmemente que hacen lo más "conveniente" para los aborígenes del Congo, por su futuro, el cual, según Popper, no existe. En todo caso, para el explorador y los suyos es menester, primero, engañar, invadir, colonizar y explotar si los fines, al cabo, son superiores, si esos fines o telos ulteriores benefician a los habitantes del Congo. Ambas instancias imponen, no obstante, su voluntad por encima de la voluntad del otro, y, a diferencia, de Kirilov o el personaje de Leaving Las Vegas, ese otro se vuelve pieza indispensable en la justificación de la existencia de uno.

En este sentido, vale la pena recordar la respuesta que Karl Popper ofrece a este difícil dilema moral (el dilema del futuro y las falsas justificaciones sacadas del presente), el cual, otra vez, coincide con el personaje de Kirilov de Dostoyevski cuando Stavogrin le pregunta:

— ¿Le gustan los niños?

- Me gustan — repuso Kirilov, pero con bastante indiferencia.

-Por lo tanto, ¿le gustará a usted la vida también?

—Sí, también la vida. ¿Por qué?

— ¿Pero no ha decidido pegarse un tiro?

- ¿Y eso qué tiene que ver? ¿Por qué juntar lo uno con lo otro? La vida es una cosa y eso es otra. La vida existe, pero la muerte no existe.

${ }_{-}$¿Cree usted en una futura vida eterna?

-No. No en una vida futura eterna, sino en una vida presente eterna (p. 297).

Leamos qué responde Karl Popper en La sociedad abierta y sus enemigos y comprendamos las razones que el filósofo austríaco esgrime contra el futuro y la intervención e imposición sobre el otro para su "improbable" beneficio:

De todos los ideales políticos quizás el más peligroso sea el de querer hacer felices a los pueblos. En efecto, lleva invaria- 
blemente a la tentativa de imponer nuestra escala de valores "superiores" a los demás, para hacerles comprender lo que a nosotros nos parece que es de la mayor importancia para su felicidad; por así decirlo, para salvar sus almas. Y lleva al utopismo y al romanticismo. Todos tenemos la plena seguridad de que nadie sería desgraciado en la comunidad hermosa y perfecta de nuestros sueños; y tampoco cabe duda de que no sería difícil traer el Cielo a la Tierra si nos amáramos unos a los otros. Pero como dije antes, cualquier tentativa de llevar el Cielo a la Tierra produce como resultado invariable el infierno. Ella engendra la intolerancia, las guerras religiosas y la salvación de las almas mediante la inquisición. Se basa además en una interpretación completamente errónea de nuestros deberes morales (p. 450).

Popper concluye diciendo que la única obligación que tenemos es la de "ayudar a aquellos que necesitan nuestra ayuda, pero no la de hacer felices a los demás" (p. 450). La exigencia política popperiana, pues, se inclina, al final, por el tipo de intervención que lleva a cabo Roger Casement en el Congo y el Putumayo al elegir como única obligación moral la de "luchar contra el sufrimiento" (p. 450) de los otros y no la de la lucha por su felicidad.

Algo similar a lo acaecido en el Congo con Henry Morton Stanley acontece en la segunda sección, "La Amazonía", cuando Roger Casement se encuentra a punto de zarpar en el Liberal rumbo al Putumayo. En el capítulo X leemos dos conversaciones fundamentales, las cuales no hacen sino poner sobre la mesa (nuevamente) la añeja discusión popperiana.

En la primera de ellas, Roger Casement le pregunta a Mr. Stirs, cónsul inglés en Iquitos, sobre el "otro drama humano" que ocurre en esa misma ciudad y frente a sus narices: "el de las niñas y niños robados a las tribus. Traídos aquí y vendidos por veinte o treinta soles a las familias" (p. 203), asunto que ya había tratado y denunciado profusamente en La casa verde. Mr. Stirs responde con crudeza: "Los heredé. Formaban parte de la casa, cuando mi antecesor, el cónsul Cazes, partió a Inglaterra. No se puede decir que los contratara porque, aquí en Iquitos, eso no se estila. Los cuatro son analfabetos y no sabrían leer ni firmar un contrato [...] En cierto sentido, para estos niños es una suerte lo que les ocurre. Ser sirvientes, quiero decir. Sería mil veces peor que 
crecieran en las tribus, comiéndose los piojos, muriendo de tercianas y cualquier peste antes de cumplir diez años" (pp. 203-204). No sólo aparece, nuevamente, como en el Congo, el problema de la legitimación a través de los contratos y las firmas, documentos que ni los aborígenes del Congo ni los indígenas del Putumayo comprenden (Mr. Stirs lo resume en una simple frase: "Aquí en Iquitos, eso no se estila"), sino que también escuchamos la justificación de la trata de los niños: su suerte, su destino, según el inglés, sería mil veces peor si no los salvamos, si no los civilizamos. Vargas Llosa, lo mismo que Casement, no responde, no asiente, no refuta, no pregunta. Expone y deja que el lector resuelva o se decante hacia el pragmatismo de Mr. Stirs o el idealismo de Roger Casement. ¿Tenemos una responsabilidad hacia los demás, estamos obligados a salvarlos según nuestro propio rasero moral, nuestro propio código de valores y, sobre todo, cuáles son los límites de nuestra libertad tratándose de la libertad del otro?

Donde, sin embargo, se complica este problema, es en largo diálogo que Casement entabla con Víctor Israel, un judío de Malta, avecindado en la Amazonía, con quien había navegado entre la frontera del Brasil y el Perú.

En primer lugar, oímos de labios del judío una apología sobre el rey del caucho, Julio C. Arana, quien muy pronto se convertirá en el mayor enemigo de Casement. Según Víctor Israel: "El hombre estaba sacando a la Amazonía del salvajismo e integrándola al mundo moderno" (p. 206). No obstante, tal y como nos enteraremos muy pronto, el gran problema de la selva (o mejor dicho: el gran problema de Europa y Estados Unidos) es la falta de trabajadores que recojan el precioso látex negro, ese "maná del cielo" que la patria peruana ha estado desperdiciando por culpa de la pereza y renuencia a colaborar de las tribus amazónicas. Roger Casement le responde:

-Bueno, ésa es una manera de ver las cosas. También hay otra.

$[\ldots]$

- ¿Qué quiere usted decir?

- Me refiero al punto de vista de los que usted llama salvajes - explicó Casement, en tono trivial, como si hablara del tiempo o los mosquitos-. Póngase en su lugar por un momento. Están allí, en sus aldeas, donde han vivido años o siglos. Un buen día llegan unos señores blancos o mestizos 
con escopetas y revólveres y les exigen abandonar a sus familias, sus cultivos, sus casas, para ir a recoger caucho a decenas o centenas de kilómetros, en beneficio de unos extraños, cuya única razón es la fuerza de que disponen. ¿Usted iría de buena gana a recoger el famoso látex, don Víctor? (p. 206).

La pregunta no está dirigida solamente a don Víctor sino a los lectores. Vargas Llosa pide un ejercicio de entropía. La respuesta de don Víctor Israel es, sin embargo, la que sigue:

— ¿Pone usted en un mismo plano a los caníbales de la Amazonía y a los pioneros, empresarios y comerciantes que trabajamos en condiciones heroicas y nos jugamos la vida por convertir estos bosques en una tierra civilizada?

[...]

- Tal vez usted y yo tengamos un concepto distinto de lo que es civilización, mi amigo - dijo Roger Casement, siempre con ese tonito de bonhomía que parecía irritar a Víctor Israel.

- Me gustaría saber cuál es su idea de la civilización - dijo Víctor Israel.

$[\ldots]$

- Se podría sintetizar diciendo que es la de una sociedad donde se respeta la propiedad privada y la libertad individual [...] Usted no piensa que la civilización sea eso. ¿O me equivoco? (p. 207).

El concepto de civilización de Roger Casement no es otro, podemos imaginar, que el mismo de Vargas Llosa, el cual parece (otra vez) extraído de La sociedad abierta y sus enemigos. Son estos, como sabemos, los dos grandes bastiones con que Popper ha fundado su exégesis: libertad individual y propiedad privada.

En el ejercicio entrópico que el novelista peruano propone de manera oblicua, don Víctor Israel obviamente fracasa: no consigue ponerse en el lugar de los aborígenes del Amazonas y, muy al contrario, se defiende recitando una sarta de justificaciones semejantes a la de Mr. Stirs y Henry Morton Stanley. ¿Nosotros, sus lectores, fracasamos o triunfamos en el ejercicio entrópico? ¿Podemos intentar al menos ver (vislumbrar) ese otro punto de vista, como propone Roger Casement? 
Aunque el primer viaje "infernal" se anuncia desde muy iniciada la novela, éste no acontece (luego de largas demoras) sino hasta el 5 de junio de 1903, esto es, en el capítulo VI de El sueño del celta. Los casi anteriores 20 años de experiencia en el Congo y sus aldeas más importantes (y habitables), no han sido, a la postre, sino un mero preámbulo de lo que está por venir. Todo lo leído (lo aprendido) sobre el Congo y sus atrocidades, no ha sido, pues, sino una mera introducción a lo que Roger Casement está a punto de experimentar y ver con sus propios ojos. Y en este sentido, "infernal" hace clara referencia al viaje infernal de Charles Marlow en Heart of Darkness, de la que El sueño del celta es hermana gemela. Una de las obvias diferencias entre ambas es, no obstante, que el relato del peruano abarca tres dimensiones, tres países y tres épocas en la vida de su personaje. El scope de El sueño del celta resulta, en este sentido, mayor, intentando cubrir la vida entera de su héroe irlandés, desde su infancia hasta su muerte.

Al igual que otras novelas de Vargas Llosa, El sueño del celta comienza in media res. Las cosas ya pasaron, pero todavía resta conocer el final. El lector es invitado a adentrarse, en una suerte de movimiento pendular, del pasado que todavía no conoce (y del que aprenderá los hechos), al posible futuro que no existe y está por suceder conforme avance en la lectura. La técnica es vieja, sabemos. El mismo Vargas Llosa la ha empleado de manera efectiva en La ciudad y los perros, La fiesta del Chivo y Conversación en La Catedral. Ahora bien, aparte de las tres grandes secciones en que se divide la novela ("El Congo", "La Amazonía" e "Irlanda"), tenemos un total de quince capítulos, ocho de los cuales ocurren dentro de la celda en Pentonville Prision en la que Roger Casement espera - los capítulos nones- la resolución del proceso del que se le ha acusado: traición y conspiración contra la patria inglesa a pesar de ser (y sentirse) irlandés, problemática que sin embargo no abordaré en estas páginas. Estos ocho capítulos nones o impares dentro de la celda van a variar en extensión, y si hay algo que cambia drásticamente en ellos es que, en primer lugar, su número de páginas aumenta conforme avanza la novela (en este sentido, el capítulo XIII será, presumiblemente, el más largo); segundo, las retrospecciones del héroe durante esos capítulos impares van a extenderse más y más para dejar (de manera inversamente proporcional) menos sitio al momento 
presente, el tiempo real de la relación entre Casement y su carcelero, el sheriff Mr. Stacey. A pesar de lo anterior, estos ocho capítulos nones o impares dentro de la celda en Pentonville nunca son tan largos como los capítulos pares, aquellos que cuentan la historia de Casement fuera de la celda, es decir, todo ese pasado suyo (su vida entera) hasta el momento del encarcelamiento.

Por lo anterior, me atrevo a sugerir que El sueño del celta se construye no sólo pendularmente (oscilando del presente en su celda con el sheriff al pasado a partir de su niñez, tal y como he dicho), sino helicoidalmente, en una suerte de movimiento en espiral que vuelve, de ramalazo, una y otra vez, a pasajes ya conocidos por el lector. Ésta es, como se verá, su mayor virtud, pero también será su mayor lastre. Veamos por qué.

En primer lugar, y para comprender mejor lo dicho, esclarezcamos la división de la novela, la cual queda repartida de la siguiente manera:

"El Congo" ( 4 capítulos nones, 3 capítulos pares: 7 en total);

"La Amazonía" ( 2 capítulos nones, 3 capítulos pares: 5 en total);

"Irlanda" ( 2 capítulos nones, 1 capítulo par: 3 en total).

(Dijimos que todos los capítulos pares son más extensos que los impares. Los pares pueden llegar a tener entre 40 hasta 65 páginas, mientras que los nones suelen tener de 12 a 20 páginas, alargándose en algunos casos conforme nos adentramos en la novela.)

Lo primero que notamos en la distribución es que las tres grandes secciones se adelgazan en su número de capítulos. También notamos que la alternancia entre los capítulos fuera y los capítulos dentro de la celda en Pentonville Prision no se rompe. Lo que sin embargo no miramos en nuestra repartición pero acontece en la novela es que, tal y como ya dije, los ocho capítulos que transcurren dentro de la cárcel a la espera de la resolución del proceso dejan, poco a poco, de tener contacto con la realidad misma de la prisión. En cambio, Vargas Llosa aprovecha los sueños, descansos, elucubraciones y meditaciones de nuestro héroe (en otras palabras, todo ese otro tiempo muerto en el que, o bien no recibe una visita, o bien no dialoga con el sheriff) para dar marcha atrás en el pasado del héroe y hacerlo describir y sopesar acciones y decisiones que pudieron o no llevarlo al momento presente. En este sentido, los capítulos nones o impares van perdiendo gradualmente contacto con la realidad presente (la de su celda) y, al mismo tiempo, van engranándose 
(encajándose) más y más con partes de la novela que ya conocíamos por la lectura de los extensos capítulos pares dedicados a contar (como se ha dicho) la vida entera de Roger Casement: desde su infancia, pasando por sus travesías en el Congo, el Putumayo amazónico e Irlanda, hasta su detención final por supuesta sedición contra Inglaterra.

El sueño del celta es, no obstante, helicoidal en dos sentidos. Primero, basados en la descripción de su estructura, los capítulos nones o impares se imbrican más y más - conforme avanza la novela - en el corpus de los capítulos pares. Segundo y más importante, la primera sección, "El Congo", arroja información sobre la segunda y tercera secciones ("La Amazonía" e "Irlanda") que, sin embargo, aún no conocemos ni leemos. Es decir, en "El Congo" se nos adelantan ya pasajes, datos y personajes que, aunque no aparecidos en la vida de Casement todavía, serán imprescindibles en las siguientes dos grandes secciones del relato. Esto queda evidentemente bien justificado desde el momento en que el lector ha sido avisado que el presente real de la novela es y ha sido siempre el del héroe encarcelado en su celda a pocos de días de conocer el veredicto sobre su apelación de clemencia. En este sentido, estructurar la obra in media res permitió a Vargas Llosa la posibilidad de arrojar luz a un futuro todavía insospechado, pero conocido al mismo tiempo (mejor dicho: un futuro reconocido por el héroe a posteriori).

Del mismo modo, la segunda sección, "La Amazonía", arrojará luz y adelantará información sobre datos, pasajes y personajes que, aun cuando no han aparecido stricto sensu en la vida de Casement (como el caso de su amante noruego Eivind/Lucifer), serán decisivos en su destino final. En este caso, sin embargo, ya no sólo se arroja luz sobre ese futuro insospechado sino que también el relato se retrotrae (cada vez que considera necesario) hacia pasajes que hemos conocido y leído en la primera sección. Así, tanto "La Amazonía" como "Irlanda" (segunda y tercera secciones de la novela) conllevan un movimiento pendular: van al futuro, se encadenan en la proairesis del relato, pero también oscilan (cuando el autor lo considera pertinente) hacia el pasado. Y es ahí precisamente donde, tal vez, vaya a surgir el problema, el lastre, de El sueño del celta. Esta forma helicoidal (de entradas y salidas como hélices que vuelven a aparecer y desaparecer en el relato repitiendo escenas ya conocidas) tiene evidentemente grandes beneficios, pero apareja el costo de cubrir un periodo en la vida de Casement (por ejemplo, Irlanda) que ya habíamos conocido vagamente a través de innumera- 
bles dosis desparramadas en las primeras dos secciones de la novela. El sueño del celta, hacia el final (y sobre todo, insisto, en su tercera sección) no consigue sino rizar el rizo de la narración. El apasionamiento con que el lector leyó la primera sección, "El Congo", e incluso la segunda, "La Amazonía", se va desvaneciendo en la tercera sección, "Irlanda". Y es que ya sabemos, comas más o comas menos, lo que entonces pasó y lo que esos acontecimientos provocaron en el destino final del protagonista. Sumado a esto, habría que añadir la tumultuosa y abrumadora información que la tercera sección aglutina haciendo (al menos en una primera lectura) casi indiscernibles a los personajes y datos de la conspiración irlandesa y alemana. La selección de materiales, qué datos se incluyen o qué datos se excluyen de la narración, es el otro problema que la novela no consiguió remediar y que, al final, no hace sino ralentizar su lectura.

Ahora bien, esta suerte de autoimpuesta preorganización y división simétrica de las secciones es algo que, como he dicho, Vargas Llosa había llevado a cabo en varios libros anteriores. Desde La tía Julia y el escribidor o El pez en el agua, hasta La fiesta del Chivo y El Paraiso en la otra esquina, el premio Nobel ha planeado y estructurado varias de sus novelas con dos características sobresalientes: la alternancia y la simetría. Ambas no son, en estricto sentido, lo mismo. La tía Julia, por ejemplo, es, como La fiesta del Chivo, alternante, pero no es simétrica, mientras que El Paraíso en la otra esquina y El sueño del celta son, en cierta medida, simétricas y alternantes.

La simetría vargasllosiana autoimpuesta resulta un elemento (en algunos casos) establecido a regañadientes. Es decir, el autor se ha fijado aparentemente una cuota de páginas más o menos idénticas en los capítulos pares y los capítulos nones. La alternancia, sin embargo, nada tiene que ver con ello. Ésta sólo indica que leeremos un capítulo paralelo y a la vez distinto, el cual no necesita tener un número específico de páginas. La simetría, por otro lado, se aboca a homologar lo más posible el número de páginas (el volumen de la narración). Tal parece, esta imposición conlleva un precio: imposible sostener siempre y en cada momento el mismo nivel de atención, intriga o suspenso. El sueño del celta sufre, pues, del mismo problema que El Paraíso en la otra esquina. Curiosamente, no sucede así en La tía Julia y el escribidor y tampoco en La fiesta del Chivo. La razón es, supongo, doble. 
La primera ya la he dicho: estas dos novelas son alternantes pero no pretenden ser simétricas, sus capítulos no están obligados a satisfacer una cuota o volumen en nombre de la simetría. La segunda razón tiene que ver con algo más sutil: la imaginación.

\section{5}

La verdad de las mentiras es, como todo en la obra y el pensamiento de Vargas Llosa, una poderosa apuesta por la imaginación, una reivindicación de la imaginación y, por eso mismo, una exaltación del arte de la ficción. La misma introducción de este hermoso libro de ensayos es una declaración de principios en toda la escala: imaginación, libertad, ficción, fabulación, arte, todo aunado e imbricado. En ella no sólo cita a Karl Popper, sino que esgrime un argumento que nadie, creo yo, ha comentado y que ni siquiera el mismo Vargas Llosa ha vuelto a desarrollar con posterioridad.

A partir del filósofo austríaco, Vargas Llosa aduce que la literatura y la historia consiguen coexistir sólo en las sociedades abiertas donde ambas disciplinas son autónomas y soberanas, donde una trata y examina las verdades históricas de manera científica, y la otra fábula "la verdad escondida en el corazón de las mentiras humanas" (p. 15). No obstante, en las sociedades cerradas (totalitarias) "la ficción y la literatura han dejado de ser cosas distintas y pasado a confundirse y suplantarse" (p. 16). A pesar de esta terrible confusión perpetrada por las facciones en el poder encargadas de mantener esas sociedades cerradas, la humanidad ha sabido crear y preservar un antídoto para salvarse. Leamos cuál es: "La imaginación ha concebido un astuto y sutil paliativo para ese divorcio inevitable entre nuestra realidad limitada y nuestros apetitos desmedidos: la ficción" (p. 19). Vargas Llosa no demerita el valor de la historia, sencillamente apuesta y exalta el valor de la ficción o el arte libre de fabular, el cual no existiría, aduce, sin libertad: "Los hombres no viven sólo de verdades; también les hace falta las mentiras: las que inventan libremente, no las que les imponen" (p. 19), y a continuación remacha con contundencia: "Es un derecho que debemos defender sin rubor. Porque jugar a las mentiras, como juegan el autor de una ficción y su lector, a las mentiras que ellos mismos fabrican bajo el imperio de sus demonios personales, es una manera de afirmar la soberanía indivi- 
dual y de defenderla cuando está amenazada; de preservar un espacio propio de libertad" (p. 20).

La tesis vargasllosiana (historia/literatura) a partir de la defensa de la libertad popperiana no sólo resulta fundamental para la comprensión política y moral de la evolución de nuestro novelista, sino que, en este caso preciso, ilumina el problema que vengo tratando: el del empobrecimiento de la imaginación a favor del enriquecimiento de la historia y documentación fidedignas.

El sueño del celta y El Paraíso en la otra esquina son, lo mismo que La guerra del fin del mundo y La fiesta del Chivo, novelas "históricas" pesar de su grandeza, la cuota artística de las dos segundas si las cuatro son, finalmente, "novelas históricas", si las cuatro son, sobre todo, novelas totalizadoras, si todas parten de hechos verídicos, documentados y más o menos fehacientes?

Mi tesis es que El sueño del celta y El Paraíso en la otra esquina adolecen, hasta cierto punto, de esa imaginación en libertad que Vargas Llosa ha defendido en sus ensayos y novelas. Junto con las restricciones autoimpuestas por el propio autor a esa libertad imaginativa que impulsa sus mejores relatos, tenemos el ya citado problema de la simetría que Vargas Llosa se impone en algunas ocasiones como camisa de fuerza, una simetría con que el premio Nobel se constriñe con el fin de satisfacer una cuota. No podría decir a cabalidad cuál es la pretendida cuota; conjeturo, sin embargo, que se trata de un prurito o pasión por el orden surgida, paradójicamente, de la lógica y el método popperianos. Insisto: esta indiscutible virtud por la sintaxis y la forma, misma que produce una proclividad hacia la simetría a ultranza, corre el riesgo de volverse (a ratos) una deficiencia, un obstáculo. El autor conoce de antemano su proyecto, las partes y la distribución del mismo; tiene, por tanto, poco espacio para los meandros, bifurcaciones y desperdicios de la imaginación. El autor ha llevado a cabo una tarea de documentación tan avasalladora (tal es la cantidad de datos y material histórico recabado), que el escritor ya no puede o no debe (a los ojos del mismo Vargas Llosa) desviarse del objetivo primordial. En otras palabras: el novelista

${ }^{6}$ Pongo históricas en entrecomillados pues no es mi intención dirimir los límites o matices que el adjetivo puede o no tener para cada crítico o lector. Empleo el término "novela histórica" en un sentido laxo, general, en un sentido a partir del cual todos nos podamos entender. 
entabla una querella a muerte, una lucha interna, entre la información y la imaginación, entre la historia estudiada y rastreada y la imaginación, entre sus "demonios personales" y los "demonios históricos", entre la abrumadora información recabada y su fantasía. Ahora bien, si a esto añadimos lo dicho sobre la posible gradual evolución en el estilo vargasllosiano (un arte de la razón y la claridad cuyo principal propósito no es otro sino comunicar, transmitir y representar fielmente el mensaje), tenemos como resultado grandes novelas que sin embargo adolecen de algo (¿la libertad sin trabas de la imaginación?). Esta carencia los lectores de Vargas Llosa quizá no la sepamos nombrar o identificar, pero sabemos que no se halla en La casa verde, La tía Julia y el escribidor o Travesuras de la niña mala.

Donde quizá podamos encontrar (entre muchos otros sitios) la genuina libertad imaginativa de Vargas Llosa en El sueño del celta es, al igual que con Gauguin en El Paraíso en la otra esquina, en esos pasajes eróticos donde el autor peruano desatiende esa camisa de fuerza para relatar, en cambio, los posibles encuentros fortuitos y amorosos de Roger Casement a lo largo de su vida, cuestión que, como se sabe, ha sido centro de controversias históricas. Aquí vale la pena traer a colación lo que Vargas Llosa dice al respecto en el epílogo del libro y también en el cuerpo de la novela.

En el epílogo leemos: "Nunca cesó ni probablemente cesará la controversia sobre los llamados Black Diaries. ¿Existieron de verdad y Roger Casement los escribió de puño y letra, con todas sus obscenidades pestilentes, o fueron falsificados por los servicios británicos para ejecutar también moral y políticamente a su antiguo diplomático, a fin de hacer un escarmiento ejemplar y disuadir a potenciales traidores? Durante decenas de años el Gobierno inglés se negó a autorizar que historiadores y grafólogos independientes examinaran los diarios [...] Cuando, hace relativamente pocos años, se levantó el secreto y los investigadores pudieron examinarlos y someter los textos a pruebas científicas, la controversia no cesó. Probablemente se prolongará mucho tiempo. Lo que no está mal. No está mal que ronde siempre un clima de incertidumbre en torno a Roger Casement, como prueba de que es imposible llegar a conocer de manera definitiva a un ser humano, totalidad que se escurre siempre de todas las redes teóricas y racionales que traten de capturarla. Mi propia impresión — la de un novelista, claro- es que Roger Casement escribió los famosos diarios pero no los vivió, no 
por lo menos integralmente, que hay en ellos mucho de exageración y ficción, que escribió ciertas cosas porque hubiera querido pero no pudo vivirlas" (p. 449). Hasta aquí, pues, eso que muchos lectores hubiésemos deseado que sucediera en los pasajes más densos de El sueño del celta, es decir, la construcción de una novela cuyo héroe histórico estuviera, sin embargo, rodeado de "un clima de incertidumbre", tal y como propone Vargas Llosa.

Esta misma cuestión de los Black Diaries aparece mencionada en el capítulo XIII de la novela cuando leemos en estilo indirecto libre lo que sigue: "Él había sido débil y sucumbido a la concupiscencia muchas veces. No tantas como había escrito en sus agendas y cuadernos de notas, aunque, sin duda, escribir lo que no se había vivido, lo que sólo se había querido vivir, era también una manera — cobarde y tímidade vivirlo y por lo tanto de rendirse a la tentación. ¿Se pagaba por ello a pesar de no haberlo disfrutado de verdad, sino de esa manera incierta e inasible como se vivían las fantasías? ¿Tendría que pagar por todo aquello que no hizo, que sólo deseó y escribió?” (p. 375).

Ambas citas (la del epílogo y la del capítulo XIII) demuestran la convicción del novelista en los presupuestos artísticos apuntalados en La verdad de las mentiras y sus demás ensayos. He aquí resuelta, creo yo, la ecuación: Vargas Llosa escribe autobiográfica o biográficamente (no importa en este caso) para poder vivir lo que no vivió o lo que no vivió "por lo menos integralmente"; Vargas Llosa tiene la convicción de que en los diarios de Casement hay, como en sus propias novelas autobiográficas, "exageración y ficción”, y que, finalmente, "escribió ciertas cosas porque hubiera querido pero no pudo vivirlas".

En la citada introducción de La verdad de las mentiras, Vargas Llosa se pregunta: “¿Qué quiere decir que una novela siempre miente? No lo que creyeron los oficiales y cadetes del Colegio Militar Leoncio Prado, donde — en apariencia, al menos - sucede mi primera novela, La ciudad y los perros, que quemaron acusándola de calumniosa a la institución. Ni lo que pensó mi primera mujer al leer otra de mis novelas, La tía Julia y el escribidor [...] Desde luego que en ambas historias hay más invenciones, tergiversaciones y exageraciones que recuerdos y que, al escribirlas, nunca pretendí ser anecdóticamente fiel a unos hechos y personas anteriores y ajenos a la novela. En ambos casos, como en todo lo que he escrito, partí de algunas experiencias aún vivas en mi memoria y estimulantes para mi imaginación y fantaseé algo que refleja de manera muy infiel esos materiales de trabajo" (p. 7). En estas 
llamadas "novelas autobiográficas" tanto como en las novelas históricas mejor logradas, Vargas Llosa fantasea y exagera más que lo que se atreve en El sueño del celta; cuanto más infiel a sus materiales de trabajo, Vargas Llosa es, paradójicamente, mejor artista, un fabulador más fértil e imaginativo. Cuanto más y mejor miente sobre sus personajes históricos, más contundentes o vivos parece que consiguen ser. En cambio, cuanto más se adhiere y se ajusta a esos "materiales de trabajo" — esa documentación largamente recabada sobre un hecho histórico o sobre un personaje-, más constreñido y sujeto parece sentirse (y expresarse). $\mathrm{Su}$ orden, su disciplina y los límites que se impone, parecen ir en contra de él en algunas ocasiones, o mejor dicho, consiguen asfixiar su ubérrima y sediciosa imaginación.

Finalmente, en la misma introducción Vargas Llosa se pregunta y se responde: “¿Hubiera podido yo, en aquellas novelas, intentar una escrupulosa exactitud con los recuerdos? Ciertamente. Pero aun si hubiera conseguido esa aburrida proeza de sólo narrar hechos ciertos y describir personajes cuyas biografías se ajustaban como un guante a la de sus modelos, mis novelas no hubieran sido, por eso, menos mentirosas o más ciertas de lo que son?” (p. 8). Vargas Llosa da en el clavo cuando explicita cómo una justa o fidedigna descripción biográfica o histórica no es, a pesar de todos los esfuerzos, más cierta o menos mentirosa cuando se habla de una novela. Ésta es, de entre otras muchas grandes lecciones vargasllosianas, una que ningún lector o novelista debería jamás olvidar. A pesar de lo dicho, y ciñéndonos a esas partes de El sueño del celta mencionadas, Vargas Llosa intenta, contra lo que él mismo ha establecido, "una escrupulosa exactitud" de los hechos históricos recabados; ajusta y describe la biografía de Casement "como un guante a la de su modelo", y cuando se atreve a no hacerlo, cuando imagina o subvierte la historia más de la cuenta, es cuando, paradójicamente, tenemos, pienso, las mejores partes de $E l$ sueño del celta ${ }^{7}$. Es entonces por culpa o debido a lo examinado hasta aquí, que la tercera sección, "Irlanda", consigue en varios pasajes la "aburrida proeza de narrar hechos ciertos". Con todo, y a pesar de lo señalado, cabe aclarar que estas deficiencias o carencias no consiguen restar su valor y grandeza a una obra

${ }^{7}$ Un fenómeno muy similar al que acontece, por ejemplo, con La guerra del fin del mundo. En esta obra es fácil adivinar cómo y cuánto su autor imagina, fabula y exagera los datos de la guerra de Canudos y la biografía de Antônio Conselheiro y sus feligreses. 
cuya voluntad formal y capacidad totalizadora es comparable a la de sus mejores novelas. El sueño del celta es, sobre todo, una valiente lección de denuncia histórica, moral y política jamás supeditada, sin embargo, a una agenda: nos enseña cómo hacer del alegato y la diatriba una obra de arte. La denuncia del El sueño del celta logra estar sabiamente supeditada a los designios artísticos y éticos de un autor en la cima de sus facultades y su libertad creadora.

\section{BiBLIOGRAFÍA}

Dostoyevski, Fyodor. Los demonios. Volumen 2. Traducción de Juan LópezMorillas. Madrid, Alianza Editorial, 2007.

Oviedo, José Miguel. Mario Vargas Llosa: La invención de una realidad. Barcelona: Seix Barral, 1982.

Popper, Karl, La sociedad abierta y sus enemigos. Traducción de Eduardo Loedel. Barcelona: Editorial Paidós, 2006.

Urroz, Eloy. "Karl Popper y Mario Vargas Llosa: ¿libertad o igualdad?" Madrid: Claves, $\mathrm{N}^{\circ}$ 208, diciembre, 2010, y Revista Universidad de México, Nueva Época, № 86, abril, 2011.

Vargas Llosa, Mario. Conversación en La Catedral. Barcelona: Seix Barral, 1981.

L La casa verde. Barcelona: Seix Barral, 1981.

- La ciudad y los perros. Barcelona: Seix Barral, 1992.

L La tía Julia y el escribidor. Barcelona: Seix Barral, 1983.

_ Historia secreta de una novela. Madrid: Tusquets Editores, 1971.

_ Carta de batalla por Tirant lo Blanc. Barcelona: Seix Barral, 1992.

La verdad de las mentiras. Barcelona: Seix Barral, 1990.

- Entre Sartre y Camus. Río Piedras, Puerto Rico: Ediciones Huracán, 1981.

García Márquez: Historia de un deicidio. Barcelona: Barral Editores, 1971.

_El pez en el agua. Memorias. Barcelona: Seix Barral, 1993.

L_ Los jefes. Los cachorros. Barcelona: Seix Barral, 1982. - Historia de Mayta. Barcelona: Seix Barral, 1984.

La Chunga. Barcelona: Seix Barral, 1986.

_L La orgía perpetua. Flaubert y "Madame Bovary". Barcelona: Seix Barral, 1981.

L La guerra del fin del mundo. Barcelona: Seix Barral, 1981. - El sueño del celta. México: Alfaguara, 2011.

Los cuadernos de don Rigoberto. Madrid: Alfaguara, 1997. - La utopía arcaica. José María Arguedas y las ficciones del indigenismo. México: Fondo de Cultura Económica, 1996.

Contra viento y marea III. Barcelona: Seix Barral, 1990. $\square$ 